\title{
Leopold von Sacher-Masoch y Marqués de Sade. Lógicas de la perversión desde de los conceptos "crítica" y "clínica" en el vitalismo de Gilles Deleuze $^{1}$
}

\author{
Leopold von Sacher-Masoch and Marquis de Sade. Logics of perversion after \\ the concepts of critical and clinical in Gilles Deleuze's Vitalism.
}

Patricio Landaeta

Centro de Estudios Avanzados. Universidad de Playa Ancha, Valparaíso, Chile

E-mail: patricio.landaeta@upla.cl

Resumen: En la literatura de Sacer-Masoch y Sade, vida y obra parecen confundirse. Ese sería el precio a pagar por la experimentación conjunta de cuerpo y escritura. Lo cierto es, como intentará plantearse, que la unidad que conforman vida y escritura en las novelas de ambos se desplaza el horizonte de la vivencia personal. A partir de los conceptos de "crítica" y "clínica" se mostrará cómo en cada caso se articula una lógica de la perversión en que se pone en juego un vitalismo literario.

Palabras claves: Sacher-Masoch, Sade, Deleuze, Deseo, Placer, Crítica, Clínica,

\begin{abstract}
In Sacher-Masoch and Sade's literature, life and work seem to be confused. That would be the price paid for the experimentation of body and writing. The truth is, as it will try to pose here, that the unity that shape life and writing in the novels of both displaces the horizon of personal experience. From the concepts of "critical" and "clinical" will be shown how fiction produces a logic of perversion in which a literary vitalism is put at stake.
\end{abstract}

Key-words: Sacher-Masoch, Sade, Deleuze, Desire, Pleasure, Critical, Clinical.

Algo que parece un requisito en la interpretación de toda novela, separar vida y obra del escritor, resulta a primera vista imposible al analizar la producción literaria de Donatien Alphonse François de Sade, más conocido como Marqués de Sade (1740-1814). Vida y obra del autor de Justine o los infortunios de la virtud parecen compenetrarse a tal punto que la ficción solo adquiere sentido cuando se pone en relación con la vida del célebre libertino. Algo semejante ocurre con quien nace casi un siglo después y es considerado sin embargo su complemento, Leopold von Sacher-Masoch (1836-1895). El autor de La venus de las pieles

\footnotetext{
${ }^{1}$ Este artículo se enmarca en el Proyecto FONDECYT Iniciación 11160327, "Literatura y multitud: cartografía conceptual de la narrativa de Nicomedes Guzmán desde la propuesta crítico-clínica de la filosofía de Gilles Deleuze y Félix Guattari.", y constituye la edición de la conferencia presentada en el Coloquio 'Psicoanálisis y literatura: inconsciente, arte y política'. Universidad Andrés Bello, Viña del Mar, Chile, 24 de julio de 2018.
} 
es otro en cuya ficción vida y obra se hallarían tan íntimamente compenetradas que se borrarían todas las distancias.

Por esta razón quizá ambos escritores han corrido la misma suerte. Desde el momento en que el psiquiatra Richard von Krafft-Ebing (1840-1902) pusiera sus nombres en la cima de los cuadros perversos, la opinión no hizo más que eclipsar su trabajo literario, convirtiendo esos nombres en clichés, en dos caras de un mismo fenómeno: la perversión sexual. Prácticamente toda la singularidad de su trabajo artístico ha quedado en segundo plano en razón de ese extendido prejuicio; toda nota característica de su diferencia ha resultado borrada, convertida en sucedáneo de la identificación del hombre, el artista y el perverso. No obstante, en Sade y Sacher-Masoch, como se intentará mostrar, la unidad que conforman vida y obra desplaza el horizonte de la vivencia, mostrando que la escritura no se contenta con narrar los gustos personales, ni con someter la vida privada al escrutinio público. Siguiendo la lectura de Gilles Deleuze (1925-1995), se intentará mostrar que ambos llevan adelante un proceso de despersonalización a través del cual se busca hacer nacer en el texto una "tercera persona" que no tiene relación con un "yo" que narra su vivencia o expone su intimidad. Lejos de aquello, esta tercera persona se deja atravesar por un devenir minoritario que solo puede tartamudear o balbucear su encuentro con el Afuera; más allá de la vivencia de un yo, se tratará de conquistar en la ficción un nombre propio. De esta manera, ambos procesos conforman una lógica de la perversión, articulada como crítica y clínica de la relación de cuerpo y escritura. Así, con el fin de comprender la singularidad del trabajo literario de Sade y Sacher-Masoch se analizará, desde el lugar que ambos escritores ocupan en el pensamiento de Gilles Deleuze, el modo específico en que vida y literatura se encuentran. En esa dirección, se intentará mostrar que la obra de cada cual construye una lógica de la perversión que en lugar de enfermos les hace merecedores del título de "médicos de la civilización".

\section{Violentar el sujeto o ¿cómo articular una la lógica de la perversión?}

El punto de arranque es sostener con determinación que la unidad dialéctica que suele fundarse entre los nombres de Sade y Sacher-Masoch resulta estéril, pues no basta con invertir la polaridad para obtener uno y otro (Cf. Deleuze, 1990, p. 10). Y si no existe tal unidad entre ambos, tampoco parece evidente que exista algo así como "sado-masoquismo", ya que la obra de cada cual revela signos y síntomas de naturaleza completamente distinta: 
[...] El genio de Sade y el genio de Masoch son de hecho diferentes; sus mundo, incomunicados; sus técnicas novelísticas, sin relación. Sade se expresa en una forma que reúne la obscenidad de las descripciones al rigor apático de las demostraciones; Masoch, en una forma que multiplica las denegaciones para hacer nacer en la frialdad un suspenso estético. La confrontación no debe desembocar necesariamente en desventaja de Masoch. (Deleuze, 1990, p. 114)

Sade y Sacher-Masoch se sitúan en las antípodas el uno respecto del otro, pero la existencia de esa distancia no es motivo para reducirles a dos manifestaciones de un mismo fenómeno, negándoles como meros contrarios. Cada uno encierra una singularidad, un carácter positivo, visible en el camino que cada cual sigue para alcanzar su nombre propio. En efecto, según Deleuze, el problema de alcanzar un nombre propio para todo artista constituye un asunto de vital importancia: "El nombre propio no designa un individuo: al contrario, un individuo sólo adquiere su verdadero nombre propio cuando se abre a las multiplicidades que lo atraviesan totalmente, tras el más severo ejercicio de despersonalización” (Deleuze, 1988, p. 43). Conquistar un nombre propio mediante un proceso de despersonalización conlleva dar un salto desde lo individual-subjetivo, anclado en la interioridad de la vivencia ejemplar, hacia lo transindividual-asubjetivo, campo de fuerzas en tensión, atravesado por signos, afectos y síntomas. Por ello suele leerse en distintos pasajes de la obra de Deleuze que la literatura no se basta a sí misma; los literatos no se ocupan de literatura, sino de otra cosa: la literatura tiene por fin vincularse con el mundo o, mejor aún, con los signos del mundo que hacen síntoma:

¿Sade y Masoch son, en este sentido, grandes clínicos? [...] Sade y Masoch nos presentan cuadros de síntomas y signos inigualables. [...] En cualquier caso, "enfermos" o clínicos, y los dos a la vez, Sade y Masoch son también grandes antropólogos, a la manera de aquellos que saben aventurar en su obra toda una concepción del hombre, de la cultura y de la naturaleza; y [son también] grandes artistas, a la manera de aquellos que saben extraer nuevas formas y crear nuevas maneras de sentir y pensar, todo un nuevo lenguaje. (Deleuze, 1990, p. 16)

Tales presupuestos dan forma a la comprensión vitalista del arte y la literatura en Gilles Deleuze, con marcada inspiración spinocista y nietzscheana. El arte solo es tal en la medida en que se vincula a la vida; en la medida en que sirve a la vida combatiendo lo que mengua su potencia. La crítica, con lo cual, no estará tanto en el contenido manifiesto de las novelas, la revolución o perversión de las prácticas sexuales, tan antigua como el mundo, sino en 
acometer la compleja tarea de la transvaloración de los valores, de demolición de lo "bueno" y "malo" en una sociedad determinada. Solo en ese sentido las novelas de ambos escritores podrán ser consideradas como un ataque radical a la sociedad que refuerza lo que existe para que nada cambie.

La novela La filosofía en el tocador, publicada en 1795, puede tenerse por un serio tratado de lógica que busca ilustrar a la juventud, tratado que nada tendría que envidiar a los que pueblan las bibliotecas universitarias, salvo por un detalle: la ilustración que persigue no es con exclusividad la ilustración de la razón, órgano supuestamente superior y rector del espíritu humano, sino la ilustración de la pasión, asumiendo que la razón a fin de cuentas no es otra cosa que una pasión más del cuerpo. Pero, ¿qué rasgos comunes poseen los diálogos? Lo que llama la atención a primera vista es que los razonamientos y frías argumentaciones que buscan convencer a la joven Eugenia son precedidos por voluptuosas descripciones de escenas eróticas en las que se enseña a desarreglar el normal (y habitual) uso del cuerpo, a interrumpir toda finalidad orgánica y virtud asociada al sexo, como si una verdadera lógica, vale decir, un pensamiento riguroso e independiente de toda consideración externa, dependiera de un preámbulo en el que el cuerpo ha sido liberado de toda función específica para consagrarle a la consecución del placer. En otras palabras, pareciera que el pensamiento solo alcanzaría su objetivo último, separarse de todo prejuicio y opinión para lograr el conocimiento verdadero, en la medida en que el cuerpo es liberado de su estado de letargo y domesticación en el que es imposible alcanzar el placer más alto. A los ojos de los educadores libertinos, la religión, la moral y las convenciones sociales coartan una verdadera experimentación del cuerpo. Por este motivo, la irreligión, la impiedad y la inhumanidad son puestos como los valores libertinos por antonomasia, en el entendido de que estos nuevos valores permiten conseguir un placer más profundo y, paralelamente, razonar y alcanzar la verdad más alta (Sade, 1998, p. 8-11). Existe, según se aprecia, un ascetismo de signo inverso: una larga vía del pecado se abre para darle a cualquiera la oportunidad de deshacerse de sí mismo, de sacudirse de encima los efectos de las prohibiciones, para devenir, finalmente, un monstruo o un perverso, vale decir, un ser cuya decisión opta por lo que está más allá de lo que ofrece la ley de la costumbre. 
Ahora bien, si el ardor se presenta como el signo característico del frío libertino sádico, el frío glacial es la marca evidente del masoquista, tal como nos lo enseña La venus de las pieles. La relación de Wanda y Severin constituye el anverso del matrimonio, ese fútil contrato de amor eterno, puesto que pacta lo que no puede jurarse: el amor eterno. Al comienzo de la novela, antes siquiera de conocer las fantasías de Severin, Wanda se explaya sobre su negativa a este contrato.

La naturaleza no conoce estabilidad en las relaciones entre hombre y mujer [...] Es solo el egoísmo del hombre que quiere enterrar la mujer como un tesoro. Todas las tentativas que han querido introducir la duración mediante ceremonias, sermones o contratos en lo más agitado del movimiento del ser humano, en el amor, han fracasado. ¿Puede usted negar que nuestro mundo cristiano esté en descomposición? Mis principios son deliberadamente paganos, quiero vivir mi vida. $[\ldots]$ ¿Pertenecer a un marido a quien no amo, bajo pretexto de que le amé alguna vez? No, no renuncio; amo a quien me place y hago feliz al que me ama. ¿Acaso es esto abominable? No; [...] Soy joven, rica y bella, y así como soy obedezco solamente a la voluptuosidad y al placer. (Sacher-Masoch, 1990, p. 136-137)

El resto del argumento es, más o menos, como sigue: Severin se halla enamorado de Wanda, pero Wanda teme que ese amor se diluya con el pasar del tiempo, ante lo cual Severin propone convertirse en el esclavo de su amada. La víctima busca libremente su verdugo en un juego que conjura que el hombre ejerza la dominación permitida por el matrimonio. De esta manera, surge la idea de un peculiar contrato que una a ambos, pero que no pondrá en juego la duración del amor, sino la sumisión absoluta de uno a otro. Un mandato en que el hombre se entrega en calidad de esclavo a la mujer y se sustrae al poder que natural y socialmente se le concedería. La glosa es la siguiente:

Contrato entre la señora Wanda von Dunajew y el señor Severin von Kusiemski: El señor Severino von Kusiemski cesa, desde el día de hoy, de ser el prometido de la señora Wanda von Dunajew, y renuncia a todos los derechos que le procuraba su calidad de amante; en revancha, se compromete, bajo palabra de honor y caballero, a ser esclavo de esta dama, en tanto que ella no le restituya su libertad. [...] Como esclavo de la señora Dunajew, deberá tomar el nombre de Gregorio, y se compromete a satisfacer todos los deseos de esta dama, a obedecer cada una de sus órdenes, a ser sumiso a su dueña, y a considerar el más mínimo signo de su favor como una gracia extraordinaria. [...] La señora Dunajew, no sólo puede castigar a su esclavo según le plazca por una mínima negligencia o una mínima falta, sino que puede maltratarle por capricho o distracción; ella tiene el derecho también de matarle si se place en ello. en suma, este deviene su propiedad absoluta. [...] Si la señora Dunajew concede algún día la libertad a su esclavo, el señor Severin von Kusiemski se compromete a olvidar todo lo que, como esclavo, haya podido vivir o sufrir, y promete no vengarse jamás, 
de ninguna manera y bajo ningún pretexto. [...] En contraparte, la señora Dunajew, en tanto que ama, promete comparecer con la mayor frecuencia vestida de pieles ante su esclavo, particularmente cuando se muestre cruel para con él. (Sacher-Masoch, 1990, pp. 194-195)

La tesis de Deleuze al respecto es que este uso desviado del contrato, el más racional de todos los instrumentos, eterniza el deseo de sumisión con el fin desplazar y aplazar la consecución del placer. A diferencia de la constate alusión a las escenas obscenas en Sade, en Sacher-Masoch existe una gran sobriedad, porque a diferencia del sádico, el masoquista solo tiene necesidad de aquel contrato para existir como tal: es cierto que deben haber señales reales de su condición, pero los golpes y torturas reales son secundarias si se comparan con el fondo: por el contrato se desplaza esa tortura, aunque pueda existir puntualmente. El sádico, por su parte, abjura de todo contrato, pudiendo tomar como víctima a cualquiera que cumpla con cierta condición: ser elementalmente un cualquiera; más todavía, la víctima debe ser cualquiera. Esa indiferencia del sádico respecto de la víctima resulta, pues, un requisito fundamental. En otras palabras, incluso si la víctima es un ser próximo o conocido (padre, madre, hijo, amigo, etc.) es necesario que le sea totalmente indiferente, como un ser anónimo. El masoquista, en cambio, se enlaza con su verdugo solamente a partir de un contrato; solo a partir de la mediación que él mismo diseña y consiente. Pero para llegar hasta ese punto, para llegar al instante en que se asegura la entera sumisión, el masoquista habrá tenido que erigirse previamente como maestro de su dueña, enseñando a su amada a alcanzar el ideal. De este modo lo señala el propio Deleuze: "El contrato masoquista no expresa solamente la necesidad del consentimiento de la víctima, sino el don de persuasión, el esfuerzo pedagógico y jurídico mediante el cual la víctima erige a su verdugo" (Deleuze, 1990, p, 67).

Así pues, se advierte que el universo del sádico y del masoquista funcionan de manera distinta y hasta opuesta. Más aún, parece difícil que ambos personajes puedan compartir escena, pues ni siquiera comparten un mismo destino. Como se aprecia en los 120 días de Sodoma y Gomorra, el libertino se place y complace en el exceso; como un fuego incombustible, de nada se puede privar un apetito insaciable. El masoquista en La venus de las pieles, a su turno, está suspendido de la voluntad de su ama y señora, que puede solicitarlo en instancias y maneras inusitadas, y que tiene el poder de interrumpir su atmósfera cuando se le plazca. Así, mientras el placer sin mediación aparece como la fuente del ardor del 
libertino, el tiempo coagulado de la espera parece ser el elemento clave para de la escena masoquista.

\section{Crítica y clínica: la perspectiva vitalista de literatura}

En el ensayo titulado Presentación de Sacher-Masoch de 1967 Deleuze propone una primera versión de la concepción vitalista de arte y literatura, a partir de la revelación de la unidad que conforman los aspectos "crítico" y "clínico" en la obra de Sade y Sacher-Masoch. El texto que sigue tomado del prefacio, de ahí las cursivas, nos lo adelanta rápidamente una primera definición de los conceptos :

Tanto se nos dijo que era lo mismo sádico y masoquista, que finalmente nos lo creímos. Hay que recomenzar, y recomenzar por la lectura de Sade y de Masoch. Puesto que el juicio clínico está repleto de prejuicios, es necesario recomenzar todo por un punto situado fuera de la clínica, el punto literario, desde donde fueron nombradas las perversiones. No es por azar que el nombre de dos escritores sirva, aquí, de designador; es posible que la crítica (en el sentido literario) y la clínica (en el sentido médico) estén determinadas a entrar en nuevas relaciones, donde la una enseñe a la otra, y recíprocamente. La sintomatología es siempre cuestión de arte. Las especificidades clínicas del sadismo y del masoquismo no son separables de los valores literarios propios de Sade y Masoch. Y, en lugar de una dialéctica que reúna precipitadamente contrarios, hay que erigir una crítica y una clínica capaces de dilucidar tanto los mecanismos verdaderamente diferenciales como las respectivas originalidades artísticas. (Deleuze, 1990, p. 11)

Este breve pero vigoroso texto enfatiza, entre otras cosas, que el único modo de restituir lo que corresponde a Sacher-Masoch y a Sade es repetir la lectura de ambos. A tal esfuerzo se consagra la arista crítica: extraer la singularidad de las novelas estableciendo para cada cual el acontecimiento que encarnan los textos. Para cumplir esta misión será necesario ir hasta el corazón del engranaje de las obras para que nos muestren cómo es que funcionan. Igualmente, algo más se añade, algo que de plano nos señala que la crítica (literaria) por si sola no es más que mera abstracción. Las novelas funcionan, tiene una manera de sostenerse literariamente: unos personajes adquieren vida con su estilo o con las marcas que la vida les imprime y que se traducen en acciones, gestos y posturas que la ficción esculpe. Pero esto no basta. Es necesario todavía que las singularidades de los personajes, las deformaciones que ponen en juego, resistan a las formas que amenazan con asfixiar la vida. Es por ello que la crítica, como destaca Philippe Mengue, es desde un primer momento, inmediatamente, 
clínica: "lo que es sorprendente, en un primer abordaje, es que la crítica literaria, que es el estudio de la creación, sea indisociable de una clínica que estaría más bien del lado de los déficits y debilitamientos de la vida" (Mengue, 2007, pp. 142-143). Las novelas de SacherMasoch y Sade, entonces, al trazar un repertorio de síntomas comunican al lector, la organización parasitaria del mundo y los mecanismos de la enfermedad, que en lugar de presentarse como un amenaza, permite conocer la vida en su elemento, en el devenir de las fuerzas del afuera que llaman constantemente a la puerta.

En Kafka. Por una literatura menor, escrito junto con Félix Guattari en 1975, se exponen las tres características del concepto de literatura menor: la primera de ellas propone que la literatura menor es una literatura que una minoría crea en el seno de una lengua mayor, produciendo una desterritorialización de la lengua o un uso intensivo o no representativo del lenguaje (Deleuze y Guattari, 1978, p. 28): se trata, en este caso, de advertir que la literatura menor lleva el lenguaje a su límite, contra las convenciones y, sobre todo, contra el canon que dictamina lo que es una "buena" literatura, originando una especie de terrorismo literario: "Escribir como un perro que escarba su hoyo, una rata que hace su madriguera. Para eso encontrar su propio punto de subdesarrollo, su propia jerga, su propio tercer mundo, su propio desierto" (Deleuze y Guattari, 1978, p. 31). En efecto, el escritor menor habita su lengua como un extranjero o como un paria, de ahí que una primaria exhortación de la literatura menor consista en "odiar toda la literatura de amos y maestros" (Deleuze y Guattari, 1978, p. 43), torciendo la función identitaria y homogeneizante de la literatura "patriarcal".

Es interesante constatar que años más tarde, en septiembre de 1988, Deleuze afirme en una entrevista concedida a Raymond Bellour y François Ewald, que sueña con volver a escribir sobre literatura, sueño que se cumplirá en Crítica y clínica al desempolvar ese proyecto de juventud en que se sitúa a Sacher-Masoch como pieza clave. Sin embargo, en esa repetición el propio proyecto sufrirá una transformación, pues el problema de la relación "literatura y resistencia" o "literatura y minoría" ocupará un lugar protagónico luego el trabajo avanzado con Guattari en Kafka. En la entrevista Deleuze sostiene lo siguiente:

He soñado a menudo con escribir una serie de estudios bajo el título general de "Crítica y Clínica": no porque los grandes autores o los grandes artistas sean enfermos, ni siquiera enfermos sublimes, ni por afán de buscar en ellos las marcas de la psicosis o de la neurosis como el secreto que su obra encierra o como su clave. No 
son enfermos sino médicos, y de una clase muy especial. ¿Por qué una perversión tan antigua como el mundo recibe su nombre de Sacher-Masoch? No porque él la "padezca", sino por que renueva sus síntomas, traza un cuadro original en el cual el contrato aparece como el signo principal, vinculando asimismo las conductas masoquistas a las minorías étnicas y al papel desempeñado por las mujeres en el interior de tales minorías: el masoquismo se convierte en un acto de resistencia, inseparable del sentido del humor característico de las minorías. Masoch es un gran sintomatólogo (Deleuze, 1995, p. 227).

La lectura de Sacher-Masoch vuelve a dar a Deleuze una pista sobre algo discutido en distintos pasajes de su trabajo individual o junto a Félix Guattari: sucede en muchas ocasiones que algunos escritores o filósofos tienen una salud pequeña. Extraños e iconoclastas, rayan en la anormalidad. Pero, a decir verdad, personajes como Sade, Sacher-Masoch, Spinoza o Nietzsche, o cualquier otro, no son enfermos, al contrario, gracias a su pequeña salud han podido erigirse como médicos de la civilización. Y eso porque más allá de su vivencia, de su enfermedad diagnosticada o de su neurosis, han trazado en sus cuerpos y en sus obras delirantes nuevos destinos para las minorías que hoy se ven sojuzgadas por toda clase de poderes. Por ello la experimentación literaria no remite a una vida íntima, por más excepcional que sea, tampoco a un secreto, por sucio que parezca. En tanto delirio o ruptura de las convenciones, la literatura traza un destino colectivo porvenir.

El último libro publicado en vida por Deleuze, Crítica y clínica (1993), recolección de textos que estará dedicado a la profundización del nexo que une literatura y minoría, avanza en esa dirección. Véase el texto introductorio, La literatura y la vida:

No se escribe con sus propias neurosis. La neurosis, la psicosis no son pasajes de vida, sino estados en los cuales se cae cuando el proceso es interrumpido, impedido, atascado. La enfermedad no es proceso, sino detención del proceso, como en el «caso de Nietzsche». Asimismo, el escritor como tal no es enfermo, sino más bien médico, médico de sí mismo y del mundo. El mundo es el ensamble de síntomas en en el que la enfermedad se confunde con el hombre. La literatura aparece entonces como una empresa de salud: [...] ¿Qué salud bastaría para liberar la vida por todas partes donde esté encarcelada por y en el hombre, por y en los organismos y los géneros? [...] La salud como literatura, como escritura, consiste en inventar un pueblo que falta. Pertenece a la función fabuladora inventar un pueblo. No se escribe con los recuerdos propios, salvo que puedan servir de origen o destino colectivos de un pueblo por venir todavía enterrado bajo sus traiciones y renuncias. (Deleuze, 2013a, p. 14-15)

En un comienzo es posible asumir cierta continuidad con las premisas de Presentación de Sacher-Masoch. No es la enfermedad del individuo la que tiene algo que 
decir. Lejos de esto, la enfermedad del mundo es la que hace señas al escritor. Pero, ¿cuál sería la enfermedad del mundo? Respondiendo a esta interrogante es como el texto dispone una nueva lectura de Sacher Masoch. Las diferencias con el texto del año 1967 se perciben claramente en Re-presentación de Masoch, texto en el que el filósofo actualiza políticamente su aproximación al escritor. Como es habitual, en el texto Deleuze se ocupa de limpiar lo que se ha dicho sobre Sacher-Masoch, de distanciar su obra de los clichés que giran en torno a su figura. Reitera por este medio la necesidad de aprender a leer los síntomas que traza, pues no se trata de restringir la mirada a lo estrictamente literario; no se trata de una hermenéutica que despejaría lo accesorio para quedarse únicamente con el texto. La literatura, como escritura, está ligada a un afuera o, mejor dicho, con el mundo que hace señas al escritormédico. La fórmula es más o menos la siguiente: el escritor hace un diagnóstico del mundo que trata sobre la enfermedad, pero de la enfermedad del Hombre. Y este diagnóstico propone una salud, pero esa salud apunta al nacimiento de un hombre nuevo (Deleuze, 2013b, p. 71). ¿Quién es y cómo se prepara el nacimiento del hombre nuevo? Es posible aventurar la siguiente conjetura: el hombre nuevo no es un hombre puro, sano, fuerte y poderoso, un mesías que vendría a salvar la humanidad y a reestablecer el orden del mundo. Más bien se trata de la muerte del Hombre y, junto a esta, de la función paterna. No solo en SacherMasoch, sino también en Lawrence y Melville Deleuze advierte que la literatura asume una tarea semejante: visibilizar el nacimiento de una nueva sociedad, la sociedad de hermanos, más allá de los géneros, capaz de erigir un poder contra el poder, un contrapoder vinculado a las minorías:

Liberar al hombre de la función de padre, hacer nacer el nuevo hombre o el hombre sin particularidades, reunir el original y la humanidad constituyendo una sociedad de los hermanos como nueva universalidad. Y es que, en la sociedad de los hermanos, la alianza reemplaza la filiación, y el pacto de sangre, la consanguinidad. El hombre es efectivamente el hermano de sangre del hombre, y la mujer, su hermana de sangre: es la comunidad de los solteros según Melville, que empuja sus miembros en un devenir ilimitado. (Deleuze, 2013c, p. 108)

Liberar los hombres de la función paterna implica una renuncia o sustracción de la virilidad. ¿No es precisamente lo que encontramos en La venus de las pieles, tanto en el contrato que estipula Severin como en el paciente trabajo previo de formación/enseñanza de Wanda? En el caso de Lawrence y Melville, Deleuze destaca no solo en esa línea el valor 
político de la homosexualidad, sino, más allá del Edipo, el del incesto, como elementos de un devenir menor que sustraen al hombre de su destino viril. Pero ¿cómo se construye esta renuncia o sustracción de la virilidad como contrapoder? "Un manifiesto de menos", texto que se incluye en el libro de Deleuze y Carmelo Bene de 1979, Superposiciones, ayuda a comprender este giro introducido por la sociedad hermanos, caracterizada por crear una alianza minoritaria universal, por descabezar la comunidad. La inquietud de Bene y otros escritores menores consiste precisamente en minorar: “cómo minorar' [...], como imponer un tratamiento menor o de minoración, para liberar devenires contra la Historia, vidas contra la cultura, pensamientos contra la doctrina, gracias o desgracias contra el dogma?” (Deleuze; Bene, 1979, p. 97). A través de una operación bien concreta de sustracción, amputación o neutralización de los elementos de poder, "no se podría ya decir que el arte tiene un poder, que es todavía un poder. Porque, al erigir una forma de conciencia minoritaria, se dirigiría a potencias de devenir, que son de otro dominio que el poder y la representación-patrón" (Deleuze, 1979, p. 125). En efecto, es justamente este asunto de las relación de las minorías con el poder lo que llevará a Deleuze a plantear una contraposición entre Sacher-Masoch y Sade.

\section{La contraposición deseo y placer}

En la filosofía de Deleuze existe una final toma de partido en favor de Sacher-Masoch en el momento en que se traza el campo de la relación “deseo y placer”, toma de posición que aquí me limitaré solamente a enunciar. La perspectiva del filósofo es la siguiente: la consecución del placer, el sufrimiento, no constituye un asunto central para el masoquista. Es por ello que Sacher-Masoch instituye el arte de desplazar los sufrimientos: "se diría que se trata de deshacer el vínculo del deseo con el placer: el placer interrumpe el deseo, de manera que la constitución del deseo como proceso debe conjurar el placer y posponerlo al infinito. [...] Masoch es el escritor que hace del suspense el resorte novelesco en estado puro, casi insoportable" (Deleuze, 2013b, p. 71-72). Silencios y largas esperas conceden a La venus una atmósfera general de tensión en el que el tiempo se coagula para el esclavo Gregorio que aguarda deseante. En esa dirección se puede leer el siguiente pasaje: 
Un mes se ha esfumado en la monótona regularidad de un duro trabajo, en una espera melancólica, arde el deseo de verla, ella que es la fuente de todos estos sufrimientos. Estoy a las órdenes del jardinero, le ayudo a podar los árboles y los setos, a trasplantar flores, a cavar y limpiar las avenidas. Comparto con él su escasa comida y su duro lecho. Me levanto y me acuesto con las gallinas, y, de vez en cuando, escucho decir que la dueña se divierte, que está rodeada de adoradores, y una vez he escuchado sus alegres carcajadas en el jardín (Sacher-Masoch, 1990, p. 200-201).

Una lenta espera conjugada con un ardiente deseo. Este cuadro se repite incesantemente en la novela, con una amada que aparece y desaparece a voluntad, y que pocas veces se sabe si es para requerir los servicios prosaicos del esclavo o para fustigarle interrumpiendo su estado natural de expectación. Es aquí que emerge un asunto muy importante desde la perspectiva deleuziana, la oposición de deseo y placer. El placer, en lugar de ser liberador, tiene un fuerte componente reterritorializador que obstruye el deseo; Deleuze dirá que lo organiza y estratifica, vale decir, que interrumpe su proceso inmanente. En Deseo y placer, carta dirigida a Michel Foucault 1977, se señala enfáticamente: el deseo, contrariamente a lo que ha pensado el psicoanálisis, no constituye ninguna carencia; es un ensamble de heterogéneos que funciona de una determinada manera. Siempre que se habla de deseo se debe entender 'agenciamiento de deseo', deseo dispuesto de tal o cual modo, en definitiva, proceso, o flujo situado; teniendo este carácter positivo, no estando ligado a la falta, el deseo es lo que ensambla o dispone el campo social en una configuración concreta, remece las estructuras sociales caducas y tiene una prioridad con respecto, por ejemplo, a los dispositivos de poder, que son en realidad efecto del deseo (Deleuze, 2008, p. 127). Se pone así de manifiesto que existe un primado del deseo sobre el poder, que opera estratificando y obstruyendo el deseo.

En efecto, para Deleuze es fundamental comprender que: "el primer dato en una sociedad es que todo se fuga o desterritorializa" (Deleuze, 2008, p. 126). Esto quiere decir que por más que exista un repertorio de prácticas, hábitos y costumbres y, en suma, toda una organización que determina lo pensable y practicable en una sociedad dada, siempre se producen fugas, huidas, experimentaciones y nuevas conexiones que resisten ese orden, que liberan el deseo. Por tanto, así como el deseo es primero en relación al poder, la vida es primera en relación con las formas de organización que disminuyen su potencia. 
Finalmente, en ese horizonte, la confrontación entre Sacher-Masoch y Sade acelera la ruptura del naturalizado eje sado-masoquista, y se plantea para Deleuze como una necesidad a la hora de conceptualizar el poder: el poder debe ser descabezado, minorizado, lo cual redunda en un confrontación con la imagen del padre, amo y maestro, demasiado patente en Sade, y con una desestimación del placer como agente de ruptura. Tal y como lo lleva a cabo el teatro de Carmelo Bene, resulta necesario minorizar al propio Sade (Deleuze, 1979, p. 89-90), abanderado de esa función paterna que se solaza en la consecución de un placer que es privativo del hombre. Solo a partir de la minoración de Sade, y de la consecuente recusación del placer, sería posible torcer la representación y, través de este gesto, enfrentarse al propio poder que somete la vida a sus formas. En efecto, liberar las potencias vida de las formas de organización del poder del padre no es algo distinto de la acción de minorizar el poder. Solo a partir del concurso de ambas acciones puede preverse la destrucción de la sociedad patriarcal y darse en lugar suyo el nacimiento de un nuevo hombre (no sujeto) de deseo.

\section{Referencias bibliográficas}

Alliez, E. (2017). «Deleuze avec Masoch». Gelas, B ; Hervé M. Deleuze et les écrivains. Nantes : Cécile Defaut.

Deleuze, G. (1967). Présentation de Sacher-Masoch. Le froid et le cruel, Léopold von Sacher-Masoch, La vénus à la fourrure. París: Minuit, 1990.

Deleuze, G. (1993). “La littérature et la vie”. Critique et Clinique. Paris: Minuit, 2013a

Deleuze, G. (1993). “Bartleby o la fórmula”. Critique et Clinique. Paris: Minuit, 2013c

Deleuze, G. (1993). "Re-Presentación de Sacher-Masoch". Critique et Clinique. Paris: Minuit, 2013b.

Deleuze, G. (1995). Conversaciones (1972-1990). Valencia: Pre-Textos

Deleuze, G. (2008). "Deseo y placer". Dos regímenes de locos (textos y entrevistas 19751995). Valencia: Pretextos, pp. 121-129.

Deleuze, G. y Guattari, F. (1978). Kafka. Por una literatura menor. México: Era. 
Deleuze, G.; Guattari, F. (1980). Mil Mesetas. Capitalismo y esquizofrenia. Valencia: PreTextos, Valencia, 1988.

Bene, C.; Deleuze, G. (1979). Superposiciones. Buenos Aires: Artes del Sur.

Mengue, Ph. (2007). «Le concept de clinique dans l'esthétique deleuzienne ». Gelas, B ; Hervé M. Deleuze et les écrivains. Nantes : Cécile Defaut.

Sade. (1998). « La philosophie dans le boudoir ». Euvres III. París : La Pléiade. 